\title{
Integrated satellite data fusion and mining for monitoring lake water quality status of the Albufera de Valencia in Spain
}

\author{
Carolina Doña ${ }^{a}, N i$-Bin Chang ${ }^{b^{*}}$, Vicente Caselles ${ }^{a}$, Juan M. Sánchez ${ }^{c}$, Antonio \\ Camacho $^{d}$, Jesús Delegido ${ }^{e}$, Benjamin W. Vannah ${ }^{b}$ \\ ${ }^{a}$ Department of Earth Physics and Thermodynamics, University of Valencia, Burjassot, Valencia, Spain \\ ${ }^{b}$ Department of Civil, Environmental, and Construction Engineering, University of Central Florida, \\ Orlando, Florida, USA \\ ${ }^{c}$ Department of Applied Physics, University of Castilla-La Mancha, Almadén, Ciudad Real, Spain \\ ${ }^{d}$ Cavanilles Institute of Biodiversity and Evolutionary Biology, University of Valencia, Burjassot, \\ Valencia, Spain. \\ ${ }^{e}$ Image Processing Laboratory, University of Valencia, Paterna, Valencia, Spain.
}

Corresponding author email: nchang@ucf.edu; Tel: (407) 754-7521

\begin{abstract}
Lake eutrophication is a critical issue in the interplay of water supply, environmental management, and ecosystem conservation. Integrated sensing, monitoring, and modeling for a holistic lake water quality assessment with respect to multiple constituents is in acute need. The aim of this paper is to develop an integrated algorithm for data fusion and mining of satellite remote sensing images to generate daily estimates of some water quality parameters of interest, such as chlorophyll $a$ concentrations and water transparency, to be applied for the assessment of the hypertrophic Albufera de Valencia. The Albufera de Valencia is the largest freshwater lake in Spain, which can often present values of chlorophyll $a$ concentration over $200 \mathrm{mg} \cdot \mathrm{m}^{-3}$ and values of transparency (Secchi Disk, SD) as low as $20 \mathrm{~cm}$. Remote sensing data from Moderate Resolution Imaging Spectroradiometer (MODIS) and Landsat Thematic Mapper (TM) and Enhance Thematic Mapper (ETM+) images were fused to carry out an integrative near-real time water quality assessment on a daily basis. Landsat images are useful to study the spatial variability of the water quality parameters, due to its spatial resolution of $30 \mathrm{~m}$, in comparison to the low spatial resolution $(250 / 500 \mathrm{~m})$ of MODIS. While Landsat offers a high spatial resolution, the low temporal resolution of 16 days is a significant drawback to achieve a near real-time monitoring system. This gap may be bridged by using MODIS images that have a high temporal resolution of 1 day, in spite of its low spatial resolution. Synthetic Landsat images were fused for dates with no Landsat overpass over the study area. Finally, with a suite of ground truth data, a few genetic programming (GP) models were derived to estimate the water quality using the fused surface reflectance data as inputs. The GP model for chlorophyll $a$ estimation yielded a $\mathrm{R}^{2}$ of 0.94 , with a Root Mean Square Error (RMSE) $=8 \mathrm{mg} \cdot \mathrm{m}^{-3}$, and the GP model for water transparency estimation using Secchi disk showed a $R^{2}$ of 0.89 , with a $\mathrm{RMSE}=4 \mathrm{~cm}$. With this effort, the spatiotemporal variations of water transparency and chlorophyll $a$ concentrations may be assessed simultaneously on a daily basis throughout the lake for environmental management.
\end{abstract}

Keywords: Water quality, Lake management, Remote sensing, Data fusion, Data mining, Machine learning 


\section{Introduction}

Eutrophication in lakes and coastal waters has long been a common environmental problem in many countries around the world. Eutrophication mostly results from an anthropogenic supply of nutrients, mainly nitrogen and phosphorus, from urban and agricultural runoff (Bricker et al., 1999). These nutrients enhance algal growth, thereby reducing water transparency and deteriorating water quality (Bricker et al., 1999). Remote sensing reflectance bands can be used in aquatic environments to detect these pollution impacts. Chlorophyll $a$ concentrations (Chl- $a$ hereafter), an indicator of phytoplankton biomass that exhibits a positive correlation with a nutrient increase, are normally determined from bio-optical observations in relatively open waters (O'Reilly et al., 2001).

Remotely sensed Chl- $a$ is particularly challenging in turbid, highly productive waters (Siegal et al., 2000; Gitelson et al., 2007, 2008), such as the coastal lake Albufera de Valencia (Spain). In many turbid water bodies, total suspended solids (TSS), either organic (mainly phytoplankton) or inorganic (sediment particles), determine water column optics. Whereas the latter can be depicted by water transparency, the former can be reflected by Chl- $a$. Monitoring water transparency informs the eutrophic status of the ecosystem because the growth of phytoplankton decreases light penetration. Paired monitoring of water transparency and Chl- $a$ can thereby reveal the general condition of the trophic status in a lake when the lack of transparency is mostly due to phytoplankton. With these indicators, water bodies can be identified through the oligotrophic to the hypereutrophic range with accuracy. The Organization for Economic Co-operation and Development (OECD, 1982) proposed different ranges of the trophic classification determined in terms of total phosphorus (TP), Chl- $a$ and water transparency measured with Secchi disk (SD), which have been widely accepted.

Encouraged by the enforcement of the European Water Framework Directive (WFD) in 2000, which establishes that all EU countries have to monitor the ecological status of their surface water bodies in order to achieve the good ecological status, there is a growing interest in using remote sensing techniques to monitor water quality variables. Remote sensing may allow a highly consistent monitoring to come with essential spatial coverage and temporal resolution when compared to the sporadic and intermittent field sampling work. Lake Albufera de Valencia, located in eastern Spain, 
is a hypertrophic water body that presents average Chl- $a$ concentrations of up to 100 $\mathrm{mg} \cdot \mathrm{m}^{-3}$, and peaks are higher than $200 \mathrm{mg} \cdot \mathrm{m}^{-3}$. Therefore it requires intensive monitoring to retrieve its water quality conditions, leading to the generation of specific measures for environmental management (Vicente and Miracle, 1992). Right after the Albufera de Valencia and its surroundings were classified as a Natural Park in 1985. López and Caselles (1987) carried out the first remote sensing study in this water body. The main goal of this study was to monitor the Chl- $a$ concentration, seston concentration, and water transparency with the aid of Thematic Mapper (TM) sensor onboard Landsat-5 satellite (López and Caselles, 1987). To retrieve the general water quality information, they applied regression techniques for estimating each parameter.

Since then, many water quality monitoring studies have focused on mapping different water quality parameters using remote sensing technologies, with varying purposes (e.g. Serrano et al., 1997; Härmä et al., 2001; Peña et al., 2004; Duan et al., 2006; Allan et al., 2011; McCullough et al., 2012). Landsat imageries were extensively used in those studies because of its relatively high spatial resolution of $30 \mathrm{~m}$ and its long period of archived data, which allows one to conduct multitemporal change detection of targeted water bodies (e.g., Mayo et al., 1995; Alle and Johnson, 1999; Olmanson et al., 2008). Yet, the sensor onboard Landsat has a limited spectral resolution and this, together with the low temporal resolution (16 days), makes it difficult to determine some of the water quality parameters accurately and timely. Sensors such as MODIS and MERIS, that have higher temporal-spectral resolution, are more suitable to monitor different water quality parameters with time-sensitive reflective spectral signatures (Peña et al., 2004; McCullogh et al., 2012); but the spatial resolution of their images is too coarse to analyze medium or small size water bodies (Mancino et al., 2009).

To study highly eutrofied lakes, such as the Albufera de Valencia, the development of the integrated data fusion and mining (IDFM) algorithm with the involvement of both Landsat and MODIS imageries might be a promising tool to get through the hurdle of near real-time monitoring (Chang et al., 2014a,b). A comparison between the main features of both sensors (i.e., Landsat and MODIS) gives rise to some insight about the possibility of sensor fusion, data fusion, or even information fusion (Table 1). To fuse the images collected by MODIS and Landsat, the data fusion algorithms working at the pixel level, such as the Temporal Adaptive Reflectance Fusion Model (STAR-FM) algorithm, may be adopted to enhance spatial, spectral, and temporal properties (Gao et 
al., 2006). Nevertheless, bio-optical or empirical algorithms, such as statistical regression and computational intelligence algorithms, are required to help classify and interpret fused remote sensing data linking the reflectance over radiance bands of the sensors with ground truth data (Peña et al., 2004, Allan et al., 2011; Domínguez et al., 2011; McCullough et al., 2012; Alonso-Fernández et al., 2013; Chang et al., 2014a, b).

Table 1. Comparison between the main features of sensors MODIS and Landsat

\begin{tabular}{lllll}
\hline \hline SENSOR & $\begin{array}{l}\text { FUSED } \\
\text { BANDS }\end{array}$ & $\begin{array}{l}\text { SPECTRAL } \\
\text { RESOLUTION } \\
(\mathbf{n m})\end{array}$ & $\begin{array}{l}\text { TEMPORAL } \\
\text { RESOLUTION } \\
(\mathbf{d a y s})\end{array}$ & $\begin{array}{l}\text { SPATIAL } \\
\text { RESOLUTION } \\
(\mathbf{m})\end{array}$ \\
\hline \hline & 1 & $450-520$ & & \\
& 2 & $520-600$ & & \\
Landsat & 3 & $630-690$ & 16 & 30 \\
TM/ETM+ & 4 & $760-900$ & & \\
& 5 & $1550-1750$ & & 500 \\
& 7 & $2080-2350$ & & 500 \\
\hline \hline & 3 & $459-479$ & & 250 \\
& 4 & $545-565$ & & 250 \\
MODIS & 1 & $620-670$ & 1 & 500 \\
& 2 & $841-876$ & & 500 \\
\hline \hline
\end{tabular}

The aim of this paper is to apply the IDFM algorithm developed by Chang et al., (2014a, b) to estimate and assess the dynamics of Chl- $a$ concentration and water transparency at the Albufera de Valencia, addressing the water quality status under the agricultural runoff impact. With such understanding of the changing water quality status, water management policy may be examined for sustainable development. In this context, fused STAR-FM Landsat-MODIS images were analyzed by a suite of genetic programming (GP) models, in order to retrieve the water quality status in the Albufera de Valencia. This endeavour leads us to explore the following science questions: 1) Can data fusion techniques be used to fill in the temporal data gaps left by Landsat and capture the spectral features of water transparency and Chl- $a$ concentrations simultaneously during the study period? 2) Can we perform data mining via GP models to effectively retrieve water transparency and Chl- $a$ concentrations based on the fused images at the same time? We hypothesized that the IDFM technique can estimate multiple water quality parameters at the same time, improving the spatial and temporal 
resolution of the water quality maps for holistic, near real-time environmental monitoring and assessment.

\section{Materials \& Methods}

\subsection{Study Area}

Albufera de Valencia is a shallow lake located in the Mediterranean coast of Valencia, Spain (39 $20^{\circ} \mathrm{N}, 0^{\circ} 20^{\prime} \mathrm{W}$ ) (Fig. 1). It is the largest natural water body on the Iberian Peninsula, and its surface is $23.2 \mathrm{Km}^{2}$ with an average depth of $1.2 \mathrm{~m}$ (Romo et al., 2008). In 1985, the lake and its surroundings were recognized as a Natural Park. In 1989, the lake was included in the Ramsar international list of protected wetlands. After that, the lake has been a popular site for numerous limnological studies (Vicente and Miracle, 1992).

The lake is connected to the Mediterranean Sea by two natural and one artificial channels called "golas", whose management is linked to the different rice growing seasons since water level in the surrounding rice fields is regulated through the lake level. Rice is the dominant crop in the area and the hydrologic cycle of the Albufera is intimately linked with the irrigation schedule and agricultural runoff. Therefore water management policy depends largely on these operations. The channel gates are open in January-March to allow the lake water level to rise mostly during this period for irrigation. During the rice growing season (April-September) the gates remain closed, with a negligible water flux into the lake. The gates open again in September-October to allow rice fields to become dry for rice harvesting. Finally, the gates are closed again in November-December to allow the flooding of the harvested rice fields to happen, favoring nutrient mineralization (Romo et al., 2008). Water inflows to the Albufera come mainly from irrigation channels bringing waters from the Turia and Júcar rivers, and several ravines which carry rain water. It also receives some treated wastewater from the urban and industrial areas nearby.

Even today, despite the improvements in the sanitary sewer systems, small amounts of untreated wastewater are still discharged into this water body. Due to these collective impacts primarily associated with changes in land use patterns, the water body of the Albufera has been polluted into a hypertrophic status with high values of Chl- $a$ exceeding $100 \mathrm{mg} \cdot \mathrm{m}^{-3}$, and low values of water transparency with Secchi Disk depths (SDDs) commonly below $20 \mathrm{~cm}$ (Soria and Vicente, 2002). The high trophic level is 
nowadays maintained not only by the external nutrient inputs, but also by the strong internal nutrient load accumulated in the lake sediments. The different sources of nutrient inputs and the differences in the sediment nutrient deposits throughout the lake, together with the effect of wind and currents, determine a certain spatial heterogeneity in the distribution of water quality variables such as the Chl- $a$ concentration and the water transparency. This variability can hardly be monitored with enough spatialtemporal resolution via regular limnological monitoring techniques, which justifies the use of remote sensing techniques.

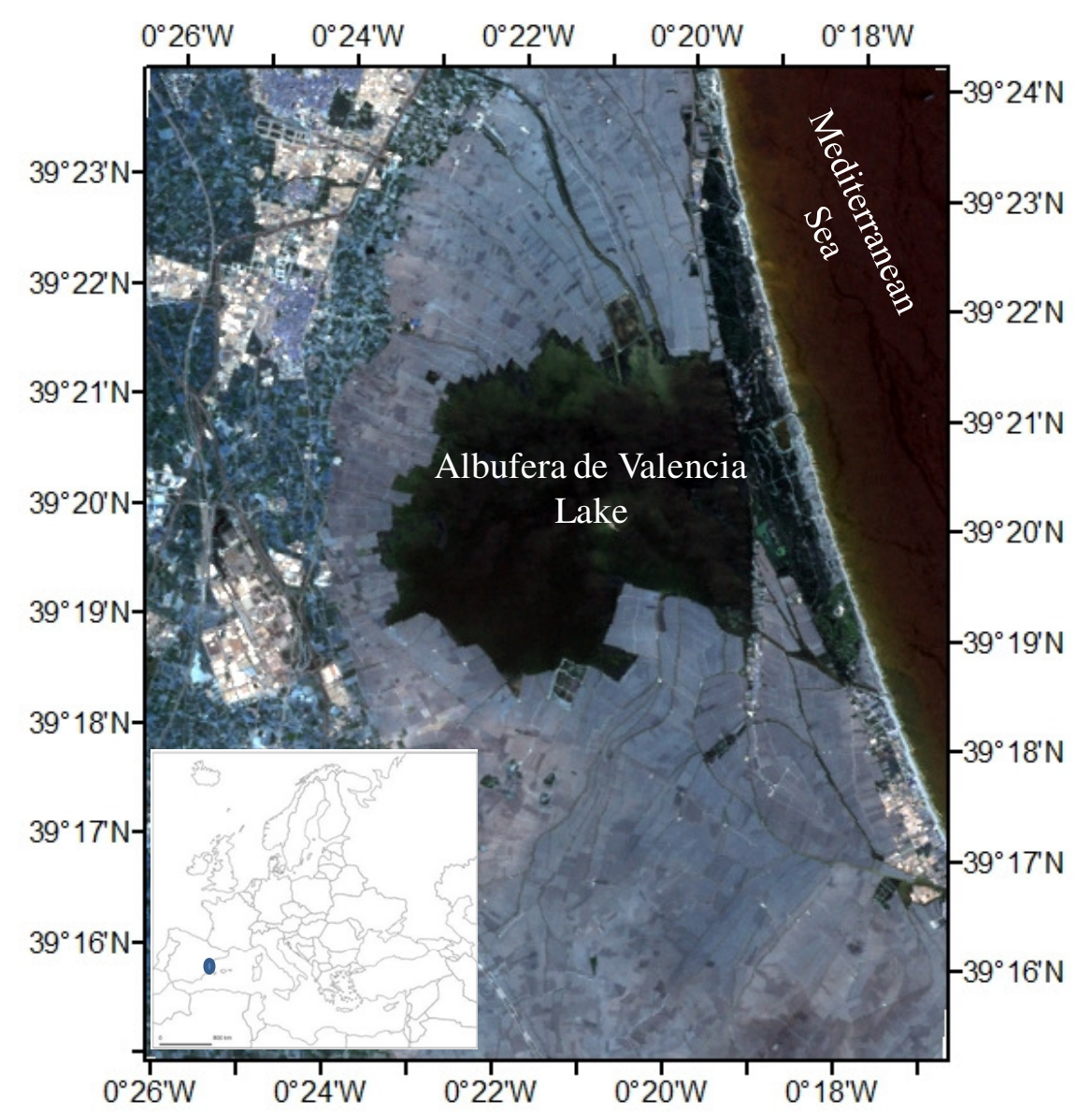

Fig. 1. Study area. Landsat true color image (RGB: (bands 3, 2 and 1)).

\subsection{Ground-Based Data}

Several field campaigns were carried out in the Albufera de Valencia during 2006 and 2011. A total of 6 sampling efforts were used in this study, including 5 sampling efforts in 2006 and one in 2011. Ground-based data were collected to reflect Chl- $a$ concentration and water transparency (Tables 2 and 3). Although more sampling records were available later on in 2011, the corresponding MODIS images contained 
some clouds in the nearby area such that we focused only on these cloud-free days for remote sensing analysis.

In these 2006 field campaigns, Chl- $a$ concentrations were measured by in-situ fluorometry with later re-calibration with laboratory data (Domínguez et al., 2011). In the 2011 field campaigns, however, samples were collected and then analyzed in the laboratory using spectrophotometric methods following the method proposed by Strickland and Parson (1968) and adapted as described in Picazo et al. (2013). Both methods fluorometry and spectrophotometry show a good agreement. Yet an underestimation of the fluorimeter measurements were observed, which could be due to the presence of phycocyanin in the water body, whose light absorption does not result in equal molar ranges of Chl- $a$ fluorescence. Additional factors can also affect this measurement such as the degradation byproducts of Chl- $a$. Nevertheless, both methods are comparable if the fluorimeter can be re-calibrated with Chl- $a$ data estimated in the laboratory (Pinto et al., 2001, Lawrenz and Richardson, 2010). The water transparency was measured as the SDD. This method has been shown to be acceptable for measuring water transparency (Margalef, 1983) and can also be used to determine the trophic level of inland water bodies (OECD, 1982).

In the field campaigns, the Chl- $a$ concentration measurements (Table 2), ranged from a minimum value of $30 \mathrm{mg} \cdot \mathrm{m}^{-3}$, in July 2006, to a maximum of $240 \mathrm{mg} \cdot \mathrm{m}^{-3}$ in April 2011. These values are far higher than the water quality standard established by the WFD for this type of water bodies, which evaluates the achievement of good ecological status. In the case of the water transparency (Table 3), collected values of SDD did not exceed $47 \mathrm{~cm}$. Therefore, the Albufera de Valencia is deemed as a hypertrophic lake requiring intensive water quality monitoring as required by the WFD to achieve the environmental goals.

Table 2. Average, maximum, minimum values, standard deviation and number of sample points, for Chl- $a$ concentration registered in the Albufera de Valencia during the sampling campaigns carried out in 2006 and 2011

\begin{tabular}{llllll}
\hline \hline & \multicolumn{2}{c}{ Chl- $\boldsymbol{a}\left(\mathbf{m g} \cdot \mathbf{m}^{-3}\right)$} & & & \\
\cline { 2 - 6 } & Avg & Max & Min & Std Dev & $\mathrm{n}$ \\
\hline \hline $\mathbf{0 6 / 2 2 / 2 0 0 6}$ & 140 & 210 & 60 & 110 & 2 \\
$\mathbf{0 6 / 2 4 / 2 0 0 6}$ & 80 & 100 & 50 & 20 & 4 \\
$\mathbf{0 7 / 1 3 / 2 0 0 6}$ & 40 & 60 & 30 & 10 & 16
\end{tabular}




\begin{tabular}{llllll}
$\mathbf{0 8 / 1 1 / 2 0 0 6}$ & 55 & 66 & 44 & 9 & 7 \\
$\mathbf{0 9 / 2 6 / 2 0 0 6}$ & 130 & 158 & 104 & 17 & 10 \\
$\mathbf{0 4 / 1 2 / 2 0 1 1}$ & 200 & 240 & 150 & 30 & 15 \\
\hline \hline
\end{tabular}

Table 3. Average, maximum, minimum values, standard deviation and total number of samples for water transparency registered in the Albufera de Valencia during the sampling campaigns carried out in 2006 and 2011

\begin{tabular}{llllll}
\hline \hline & \multicolumn{2}{l}{ Water transparency $(\mathbf{c m})$} & & \\
\cline { 2 - 6 } & Avg & Max & Min & Std Dev & $n$ \\
\hline \hline $\mathbf{0 6 / 2 2 / 2 0 0 6}$ & 36 & 41 & 29 & 6 & 6 \\
$\mathbf{0 6 / 2 4 / 2 0 0 6}$ & 39 & 44 & 36 & 4 & 3 \\
$\mathbf{0 7 / 1 3 / 2 0 0 6}$ & 40 & 47 & 33 & 4 & 15 \\
$\mathbf{0 8 / 1 1 / 2 0 0 6}$ & 39 & 44 & 34 & 3 & 7 \\
$\mathbf{0 9 / 2 6 / 2 0 0 6}$ & 24 & 28 & 20 & 3 & 10 \\
$\mathbf{0 4 / 1 2 / 2 0 1 1}$ & 14 & 20 & 10 & 3 & 15 \\
\hline \hline
\end{tabular}

\subsection{Remote Sensing Data Collection}

Landsat TM and ETM+ as well as MODIS, on board Landsat 5, Landsat 7 and Terra platforms, respectively, were the sensors used to conduct this study. All the images are available, free of charge, in the webpage of the United States Geological Survey. Landsat images were downloaded from the Glovis visor (http://glovis.usgs.gov/) and the MODIS images from the web interface of the MODIS reprojection tool (https://mrtweb.cr.usgs.gov/). With this tool the MODIS Level-2G, Level-3, and Level-4 land data products are referenced to a global tiling scheme, and tiles are non-overlapping (Dwyer et al., 2006), i.e. these images does not present the bow tie effect. This means that the scans are partially overlapping at off nadir angles and this effect occurs at the border of each scene. This effect is presented in MODIS level 1 and 2 products. These products can be corrected using the MODIS Reprojection Tool Swat, but not level 2G products. Even though the bow tie effect is corrected, sometimes these images present distortion in the pixel values. We checked every single image to screen out this kind of issue. Finally, we used a total of 28 images, (19 from MODIS and 9 from Landsat). The downloaded images correspond to the synchronous ground data sampling campaigns and the extra images necessary to carry out the data fusion processing (Table 4). 
Table 4. MODIS and Landsat images used in this work for the days of years (DOY) 2006 and 2011

\begin{tabular}{|c|c|c|c|c|c|c|c|c|c|c|c|c|c|c|c|c|c|c|c|c|}
\hline DOY & & & & & & & & & & & & & & & & & DOY & & & \\
\hline & 173 & $175^{*}$ & 194* & 198 & 221 & $223^{*}$ & 237 & 239 & 240 & 242 & 251 & 259 & 260 & 262 & $269^{*}$ & 278 & & 99 & $102^{*}$ & 116 \\
\hline 2006 & & & & & & & & & & & & & & & & & 2011 & & & \\
\hline MODIS & $\mathrm{X}$ & $\mathrm{X}$ & $\mathrm{X}$ & $\mathrm{X}$ & $\mathrm{X}$ & $\mathrm{X}$ & $\mathrm{X}$ & $\mathrm{X}$ & $\mathrm{X}$ & $\mathrm{X}$ & $\mathrm{X}$ & $\mathrm{X}$ & $\mathrm{X}$ & $\mathrm{X}$ & $\mathrm{X}$ & $\mathrm{X}$ & MODIS & $\mathrm{x}$ & $\mathrm{X}$ & $\mathrm{X}$ \\
\hline LANDSAT & $\mathrm{X}$ & & & $\mathrm{x}$ & $\mathrm{x}$ & & $\mathrm{x}$ & & & & & & & $\mathrm{X}$ & $\mathrm{X}$ & $\mathrm{X}$ & LANDSAT & $\mathrm{x}$ & & $\mathrm{X}$ \\
\hline
\end{tabular}

* days with ground-based data

\subsection{Remote Sensing Image Processing}

The steps needed to carry out image processing for the MODIS and Landsat images individually before performing the data fusion are shown in Fig. 2. The selected MODIS product was the MOD-09GA/GQ daily reflectance data with 500/250 m resolution, while the Landsat images were the radiometrically and geometrically terrain corrected product - L1T, with 30 meter resolution. This type of Landsat data is depicted in digital numbers and need to be transformed to surface reflectance values. The atmospheric layer between the surface and the satellite sensors disturbs the signal and an atmospheric correction of the Landsat images was necessary to remove this atmospheric disturbance. In this work, the $6 \mathrm{~S}$ radiative transfer code was used. It is an improved version of $5 \mathrm{~S}$ and was developed according to the radiative transfer theory (Vermote et al., 1997, Masek et al., 2006). In addition, the MODIS images were resampled to a pixel size of $30 \mathrm{~m}$, applying the nearest neighbor resample method. Both types of images were resampled to UTM zone $31 \mathrm{~N}$, and then a water mask was applied to separate the water-land pixels. Finally, Landsat and MODIS images were obtained with the same pixel size $(30 \mathrm{~m})$ for the subsequent data fusion over the entire study area. After finishing the image processing, all the images were visually compared to check if they were co-registered correctly.

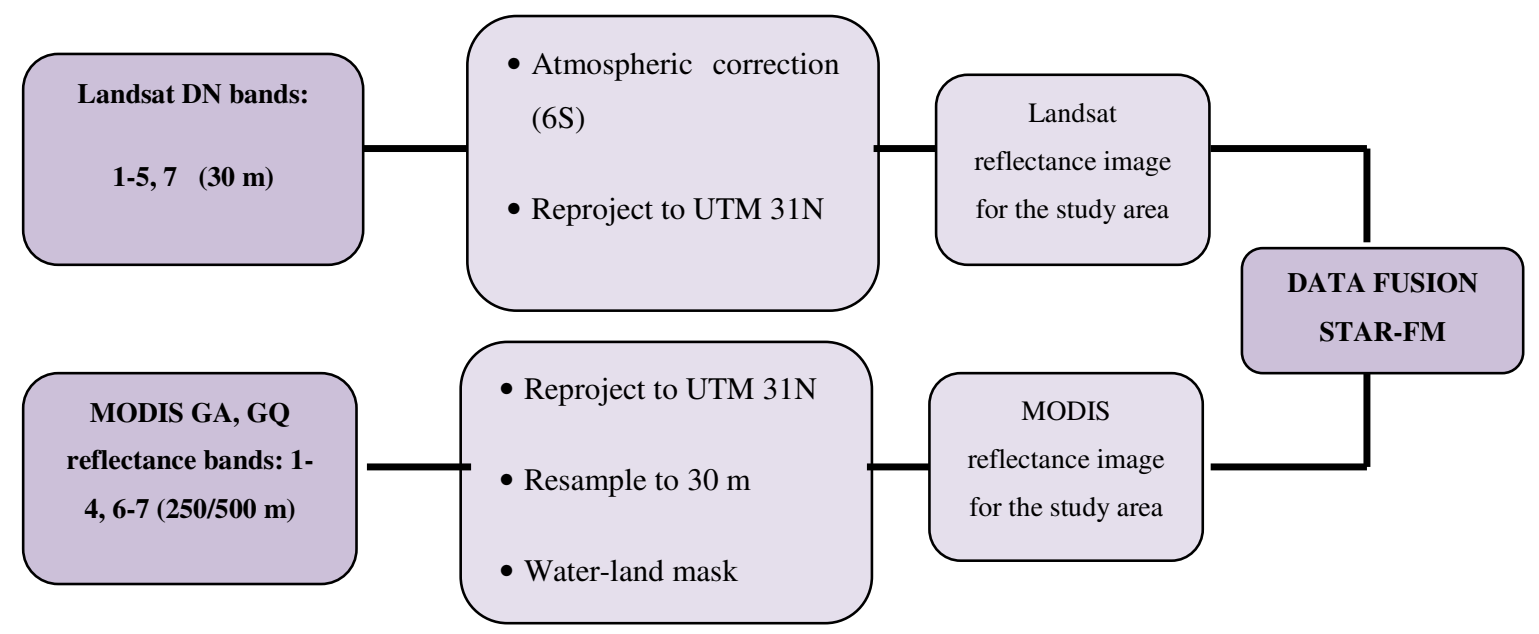


Fig. 2 Steps needed to carry out the image processing of the MODIS and Landsat images

\subsection{Data Fusion}

The application of data fusion for remotely sensed images involves the algorithmic combination of spectral, temporal, or spatial characteristics from two or more images (Genderen and Pohl, 1994; Caselles et al., 1998). The fused or synthetic image possesses the best characteristics of their parent images to provide higher monitoring power. Given that data fusion can focus on one or more properties (spectral, temporal, spatial, etc.) offered by the parent images, an obvious motivation for data fusion comes from the fact that the fused images may incorporate more information than the original images (Pohl and Genderen, 1998). There are a number of methods for fusing images. One way to differentiate between data fusion techniques is to classify methods according to when data fusion is performed. According to Pohl and Genderen (1998), the three primary categories of data fusion by processing level are: pixel level, feature level, and decision level.

STAR-FM, which was used in our analysis, is the fusion software at the pixel level produced by the National Aeronautics and Space Administration of the United States (Gao et al., 2006). The software can be downloaded from the Landsat Ecosystem $\begin{array}{lllll}\text { Disturbance } & \text { Adaptive } & \text { Processing } & \text { System } & \text { web }\end{array}$ (http://ledaps.nascom.nasa.gov/tools/tools.html). It was designed for the fusion of satellite images such as Landsat and MODIS. The methodology incorporates fusion at the pixel level between images that are spectrally similar and spatially correlated. Fusion at the pixel level is primarily done by the combination of physical attributes characterized by the pixel, such as spatial or spectral information. Since spectral similarities are required, the techniques used can be applied to any sensors sharing overlapping, spectrally similar bands, such as MODIS ocean color and MERIS (Chang et al., 2014b). For fusion between Landsat and MODIS images, at least a LandsatMODIS input pair for the same day are required, followed by a MODIS image corresponding to the next day for which the fused Landsat images can be generated via 
data fusion. Although STAR-FM algorithm can work based on a single LandsatMODIS input pair (pre or post conditions, depending on whether the pair image date is from before or after the predicted image date), we used two input pairs (pre and post conditions) to obtain better daily images (Gao et al., 2006). Thus, a suite of images are required to complete the data fusion: a pair (Landsat-MODIS) to build a fusion horizon in every 16 days apart and a series of daily MODIS images to fit in the gap of 14 days in the middle. The predicted images to fit in the gap of 14 days in the middle are called fused or synthetic Landsat image.

It should be noted that a primary limitation of STAR-FM is cloud-cover. If clouds obstruct the area, then the reflectance of the ground cannot be observed. Furthermore, applying this methodology to water may not be feasible under highly dynamic conditions, such as swift currents, rapid algal bloom growth, and highly windy conditions. The effect of these conditions is exacerbated when selecting a MODIS and Landsat input pair that is taken hours apart on the same day. These are, however, not common conditions for the studied lake.

\subsection{Water Quality Mapping}

Genetic programming (GP) developed based on genetic algorithms is a subclass of evolutionary computation techniques designed to search for the best fit to perform a user-defined task. GP can decode system behaviors based on empirical data for symbolic regression, uncover relationships, and make inferences using association, path analysis, classification, clustering, and forecasting (Seifert, 2004). One principal advantage of GP is that the solution methodology aims to learn the relationship between the inputs and outputs without any prior knowledge or preconceptions. Thus, the burden of the discovery process is primarily handled by GP, with reduced contribution from preprocessing of data such as random grouping of data for model calibration and validation by the user. In this study, the user-defined task is to develop a GP model or program that uses the inputs of fused surface reflectance data associated with common bands to predict the outputs, which are Chl- $a$ concentration and water transparency.

The fundamental concepts for GP are rooted in evolutionary computing, which relies on Darwinian principles of survival to have the fittest programs reproduce, while subject to genetic operations including crossover, mutation, and reproduction. In GP, a program is a structured set of functions that are ordered as a hierarchical tree (Koza, 
1992). The fittest program is a set of instructions comprising highly nonlinear functions that carry out the objective to achieve the goodness-of-fit in an optimal and accurate manner. The end result yields a well-fitted nonlinear equation emergent from natural selection processes and genetic operations selected from a suite of fittest programs.

The ground truth data set was divided into two subsets for GP model training (2/3 of total data) and validation (1/3 of total data), each of which is a supervised learning process leading to the determination of the best thirty nonlinear equations based on the best fit over the training and validation data subsets. Mapping of the Chl- $a$ concentrations and the water transparency with their respective reflectance values of each of fused band may be fulfilled in two independent GP analyses.

Discipulus $^{\circledR}$ (Francone, 1998) was the software used in this study to perform GP. The program operates using the above stated procedures; however, programs are selected for genetic operations using tournament selection, which selects a program of highest fitness based upon two or more randomly chosen programs from the population. The resulting white-box GP model may allow one to draw inferences upon the mathematical processes relating the inputs and outputs, but such interpretations are often difficult to make for complex models, which can be further muddled with code bloat.

\subsection{Statistical Evaluation}

Statistical analyses for the comparison between predictions and field observations were conducted using four indices as described in Willmott (1982), as shown below (Eq. 1-4). Low values of these statistical indices imply better performance in the estimation of these variables.

1. the root of mean square error (RMSE), in which $\left(\mathrm{P}_{\mathrm{i}}\right)$ and $\left(\mathrm{O}_{\mathrm{i}}\right)$ are the predicted and the observed values, respectively, and $n$ is the total number of observations:

$$
\text { RMSE }=\sqrt{\sum_{i=1}^{n} \frac{\left(P_{i}-O_{i}\right)^{2}}{n}}
$$

2. the mean absolute difference (MAD)

$$
\mathrm{MAD}=\sum_{\mathrm{i}=1}^{\mathrm{n}} \frac{\left|\mathrm{P}_{\mathrm{i}}-\mathrm{O}_{\mathrm{i}}\right|}{\mathrm{n}}
$$

3. the mean absolute deviation percent (MADP) 


$$
\text { MADP }=\frac{\sum_{i=1}^{n}\left|\mathrm{P}_{\mathrm{i}}-\mathrm{O}_{\mathrm{i}}\right|}{\sum_{i=1}^{n} \mathrm{O}_{\mathrm{i}}}
$$

4. the biased estimator (BIAS):

$$
\mathrm{BIAS}=\sum_{\mathrm{i}=1}^{\mathrm{n}} \frac{\left(\mathrm{P}_{\mathrm{i}}-\mathrm{O}_{\mathrm{i}}\right)}{\mathrm{n}}
$$

\section{Results and Discussion}

\subsection{Data Fusion}

For the purpose of demonstration, we show the fused image in September 2006 (days of year-DOY-269) in Fig. 3. Note that Landsat 7 images have scan line errors resulting in strips which require pretreatment before fusion. To solve the ETM+ gap problem, we applied a bilinear interpolation method for pretreatment (ESRI, 2013). For the purpose of comparison, the pre-condition date is the DOY 262 with and without pretreatment (Fig. 3 a, d), respectively, and the post-condition date is the DOY 278 with and without pretreatment (Fig. 3 c, f), respectively. Final synthetic images with and without pretreatment are shown in Fig. 3 b, e. All this is indicative that the fused results were heavily affected by the problem with the strips in the Landsat ETM+ images.

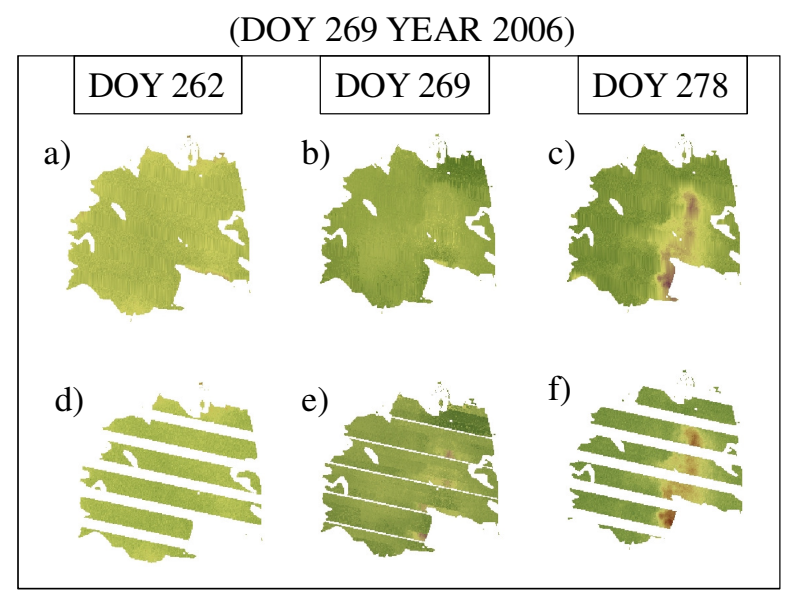

Fig. 3. Original ETM+ images for the DOY 262 and 278 with (a, c) and without (d, f) pretreatment and, the corresponding synthetic images obtained for the DOY 269 with (b) and without (e) pretreatment.

\subsection{Data Mining with GP Models}


For the estimation of Chl- $a$ concentration and water transparency, Discipulus ${ }^{\circledR}$ software package was used to help generate the nonlinear regression equations with respect to the ground-truth data associated with each of the two water quality constituents of interest (Chl- $a$ concentration and water transparency). Each of the nonlinear regression analyses derived by the GP modeling process is based on two subsets of data; one for the training and the other for the validation of the proposed GP models selected by Discipulus ${ }^{\circledR}$. In the case of the Chl- $a$ mapping, we had 52 samples in association with their respective fused reflectance values. 36 out of the 52 data points were applied for the training, whereas the rest of 16 were utilized for model validation. The best GP model was screened and selected for the Chl- $a$ mapping (see Appendix 1). It is observed that the derived GP model for mapping Chl- $a$ is credible since it has adjusted $\mathrm{R}^{2}$ values of 0.94 and 0.98 , associated with the training and validation processes, respectively (Fig. 4). The statistical values obtained for the validation (Table 6) showed the accurate estimation of Chl- $a$ concentrations with an MADP of $6 \%$ and a RMSE of $8 \mathrm{mg} \cdot \mathrm{m}^{-3}$ relative to the average values of ground-truth data of $120 \mathrm{mg} \cdot \mathrm{m}^{-3}$.

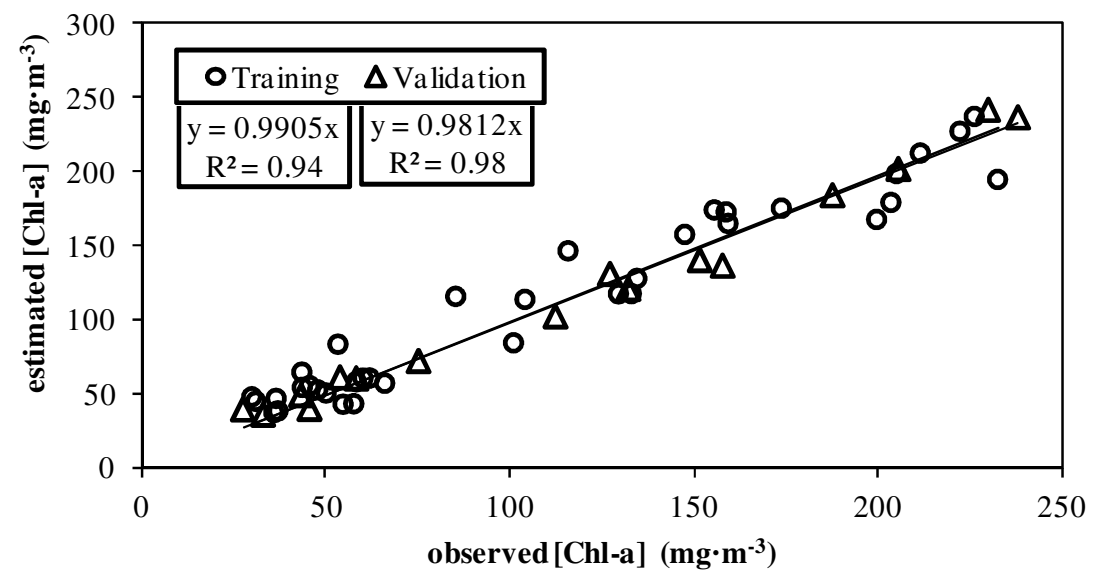

Fig. 4. Estimated versus observed Chl- $a$ concentrations based on the derived GP model with respect to the training and validation data sets

In the case of the estimation of water transparency, the best GP model was screened and selected for the water transparency mapping (see Appendix 2). The derived GP model for mapping water transparency is still credible since it has adjusted $\mathrm{R}^{2}$ values of 0.89 and 0.82 , associated with the training and validation processes, respectively (Fig. 5). The average value of the water transparency based on the validation data set is $34 \mathrm{~cm}$ along with a standard deviation of around $10 \mathrm{~cm}$ (Table 5). In addition, the statistics of the derived GP model for the water transparency mapping 
based on the validation data set presented an RMSE of $4 \mathrm{~cm}$ and an MADP of $\pm 9 \%$. Given the range in the water transparency values it might be difficult to obtain an algorithm throughout regression techniques (Domínguez et al., 2012). However, GP modeling techniques help solve this issue without the requisite of acquiring additional data sets to increase the range of the water transparency values.

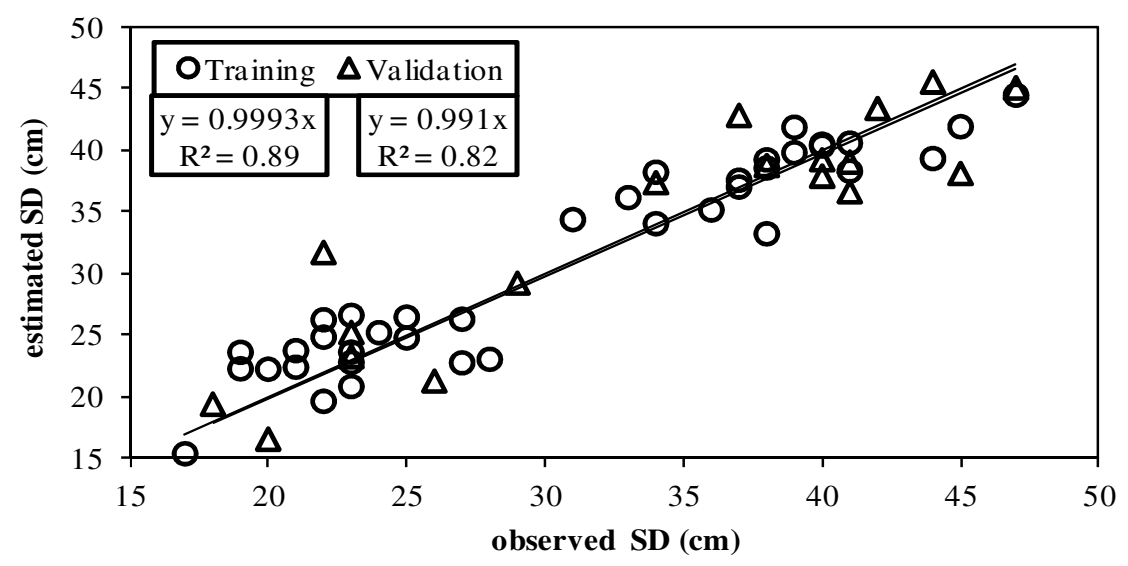

Fig. 5. Estimated versus observed water transparency (Secchi Disk depths) based on the proposed GP model with respect to the training and validation data sets

Table 6. Summary of the statistical assessment between predicted and observed Chl- $a$ and water transparency [SDD] using the validation data set

\begin{tabular}{lll}
\hline Statistic & $\begin{array}{l}{[\mathbf{C h l}-\boldsymbol{a}]} \\
\left(\mathbf{m g} \cdot \mathbf{m}^{-3}\right)\end{array}$ & SDD $(\mathbf{c m})$ \\
\hline \hline Observed & 120 & 30 \\
Values & 70 & 10 \\
Std Dev $_{\text {obs }}$ & & 34 \\
Predicted & 120 & 9 \\
Values & 70 & -0.003 \\
Std Dev pred & 70 & 3 \\
BIAS & -2 & 4 \\
MAD & 7 & 9 \\
RMSE & 8 & \\
MADP $(\%)$ & 6 & \\
\hline \hline
\end{tabular}

Note: Std Dev obs and Std Dev pred stand for the standard deviation of observed and predicted values, respectively.

Regression techniques were also evaluated to highlight the potential of GP models in this water body. In the case of the Chl- $a$ estimation, regression coefficients lower than 0.50 were obtained for all the band combinations tested, with exception of band 2 which presented a $\mathrm{r}^{2}$ value of 0.6. Regarding the water transparency (SDD) estimation, we could not define a good relationship between the reflectance bands and this variable 
with this kind of regression techniques, as already pointed out by López-García and Caselles (1987). The main cause of this fact in the Albufera de Vaelncia is that the very low water transparency values and the high fluctuations of the groundwater data complicate the model calibration. This was evidenced by Doña et al. (2014) that carried out a companion study in the same water body obtaining a relationship between TM band 2 reflectance and SDD by means of regression techniques.

\subsection{Generation of Concentration Maps}

With the GP models available based on daily fused images, mapping the spatiotemporal variations of Chl- $a$ concentration and water transparency on a daily basis became feasible. For illustration, the multi-sensor GP models developed above were applied based on the proposed data fusion process using surface reflectance values collected from mostly cloud-free days in August and September of 2006. The Chl-a concentration and water transparency SD maps are shown in ¡Error! No se encuentra el origen de la referencia. for the dates missing high-resolution Landsat images:

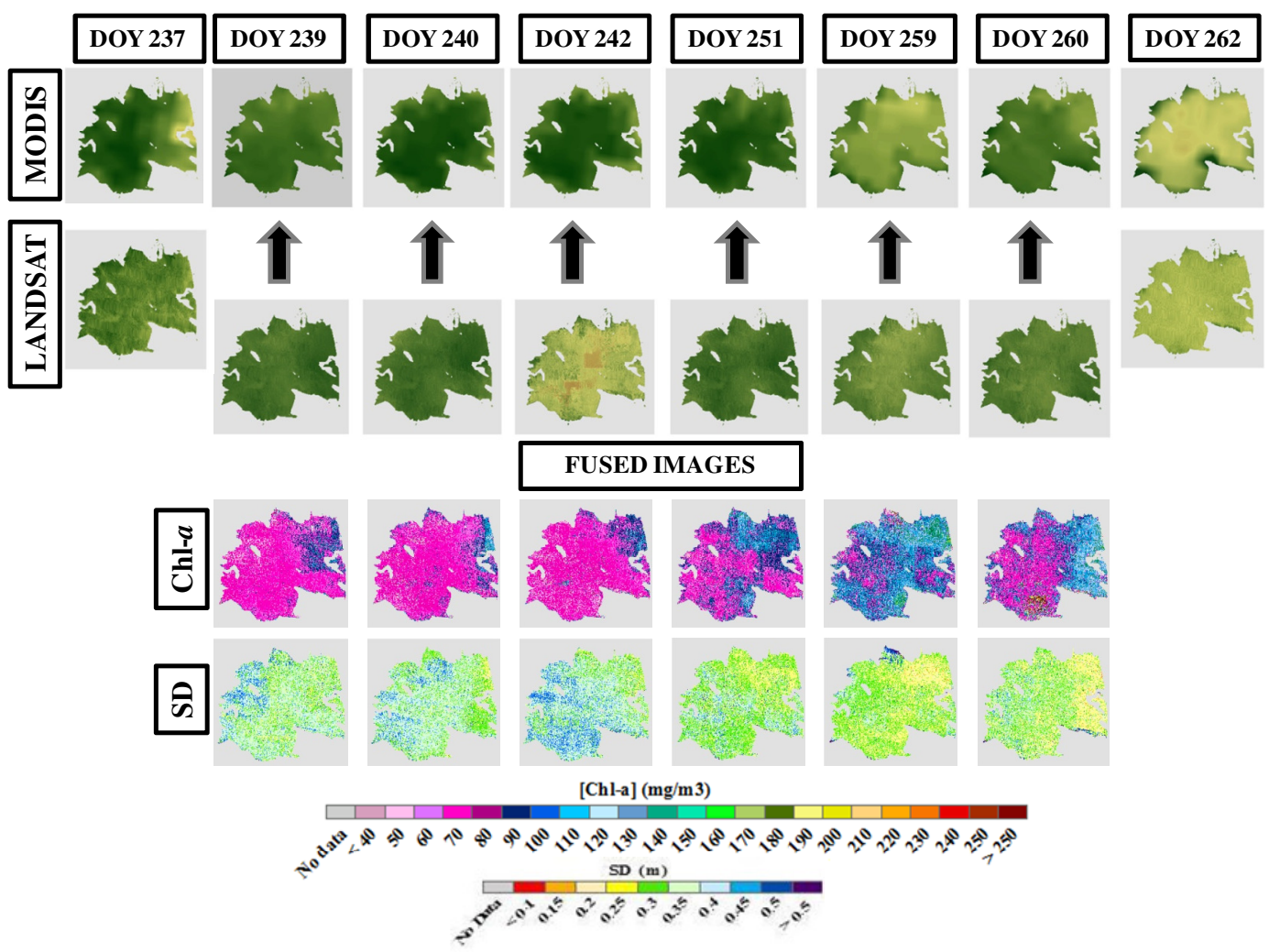

Fig. 6. Data fusion of Chl- $a$ concentration and transparency (SD) cloud free maps generated for the study period of August-September 2006 
One set of snapshots corresponding to July-September 2006 was selected for the purpose of demonstration (Fig. 7). It is indicative that the seasonality effect of the Albufera de Valencia is dependent to the different rice growing seasons (Romo et al., 2008). In July-September, the channel gates are normally closed during the rice growing period. This implies that water circulation is very low. Yet the level of water circulation would increase after the harvesting season in September-October when the gates are opened again. Romo et al. (2008) observed that the maximum values of Chl- $a$ concentration in the Albufera de Valencia may be tied to the critical months of April and September coincidently. When the gates are closed, it results in a longer period of hydrologic stability during the rice culture stage. Since no discharge is allowed into the sea for cleaning-up part of the phytoplankton, $\mathrm{Chl} a$ concentrations increase over time due to the lower level of water circulation from May to Aug (Fig. 7 a, b, c, d), and the nutrient needs are mainly sustained by the internal nutrient load recycling. Note that Chl $a$ concentrations in the first image (Fig. 7 a) are even higher than those of the second image (Fig. $7 \mathrm{~b}$ ) due to rainfall effects. In addition, the gap filling procedure to solve the issue with Landsat 7 stripes might introduce effects on the different variable maps (Fig. 7 c).

To confirm this hypothesis associated with Fig. 7 b, rainfall data were collected for these months via the Integrated Information Water System (SIA) geographic visor tool available in the webpage of the Spanish Ministry of Agriculture, Food and Environment. We found a significant storm $50 \mathrm{~mm} \cdot$ day $^{-1}$ in south part of the Natural Park in the DOY 266 which made the water quality worsen in the September image (DOY 269). 

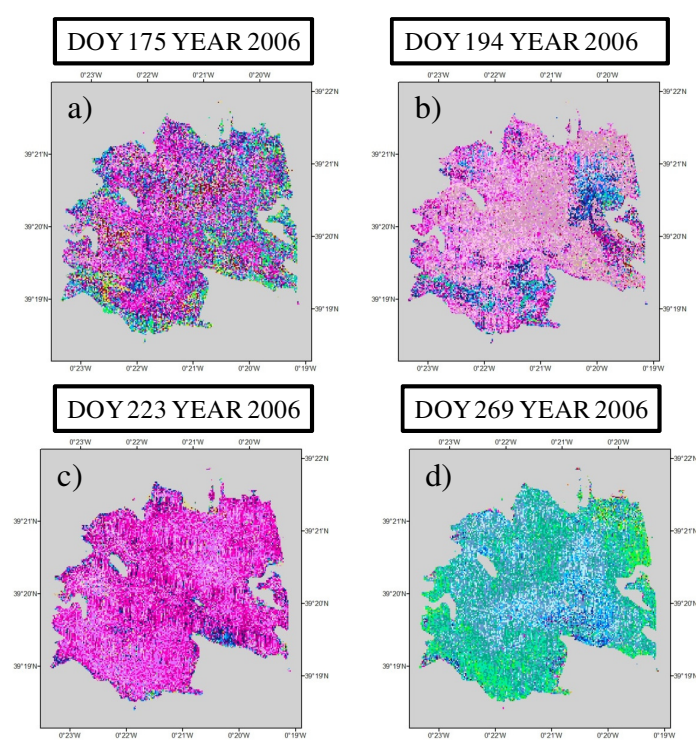

$[\mathrm{Chl}-a]\left(\mathrm{mg} \cdot \mathrm{m}^{-3}\right)$
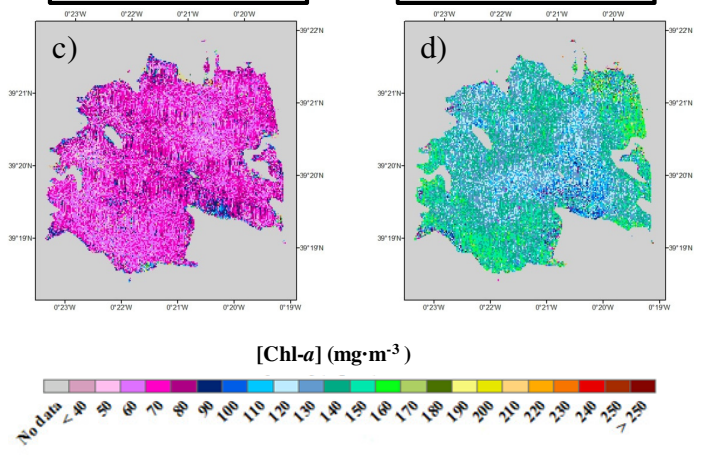

Fig. 7. Chl- $a$ concentration maps of the Albufera de Valencia, given after applying the obtained algorithm to the fused images

Water transparency maps (Fig. 8) corroborate that low SDD values generally predominate in this water body, with the lower values of SDD corresponding to the higher values of Chl- $a$ concentration, as expected. With these two figures (Fig. 7 and 8), their spatial coupling and temporal correlation are well described even in this heterogeneous environment. To evidence this contrast, the different hydrological sectors of the lake proposed by Soria and Vicente (2002) may be adopted (see the middle panel of Fig. 9). These authors differentiated the lake into 5 sectors, depending on the observed water circulation, quantity of flux, quality of water and other features. 


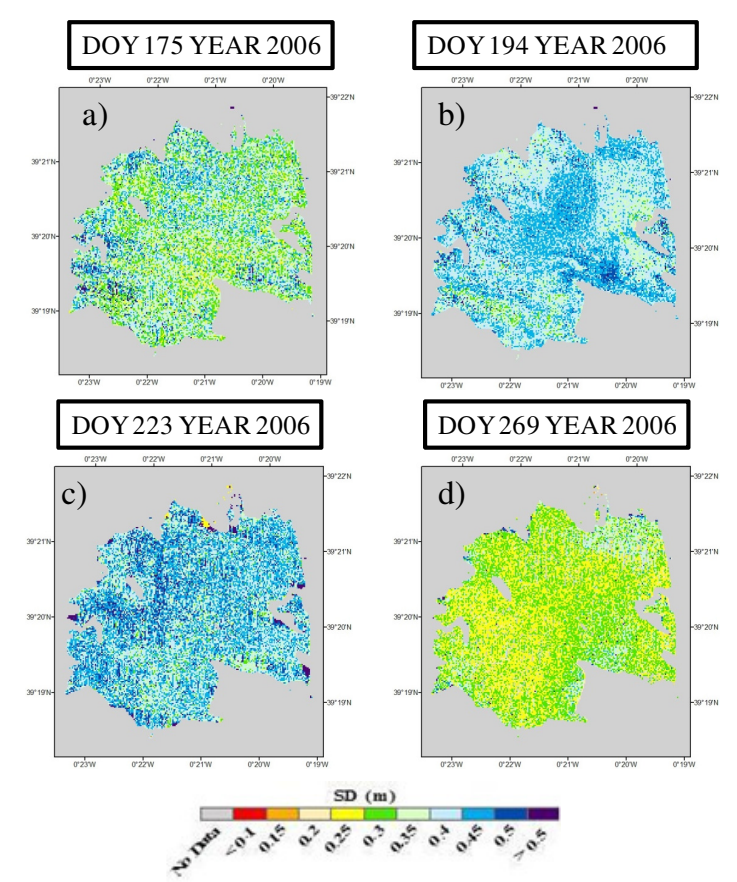

Fig. 8. Water transparency maps (SD, in $\mathrm{m}$ ) of Albufera de Valencia, obtained by applying the developed algorithm to the fused images

The left and right panels of Fig. 9 show the contrast maps of Chl- $a$ concentrations and water transparency in the DOY 112 of 2011, respectively. Based on the map of the different sectors presented in the central panel of the figure, it can be observed that the Northwest and West sectors present the higher values of Chl- $a$ concentration and lower water transparency, due to low water circulation. Conversely, the lower values of Chl- $a$ concentrations appear, with higher water transparency, in the northeast and southeast areas due to the proximity of the gates near these areas, allowing higher water flux at this region. The southwest area could be considered a transition zone, as shown in Figure 9.

DOY 102 YEAR 2011

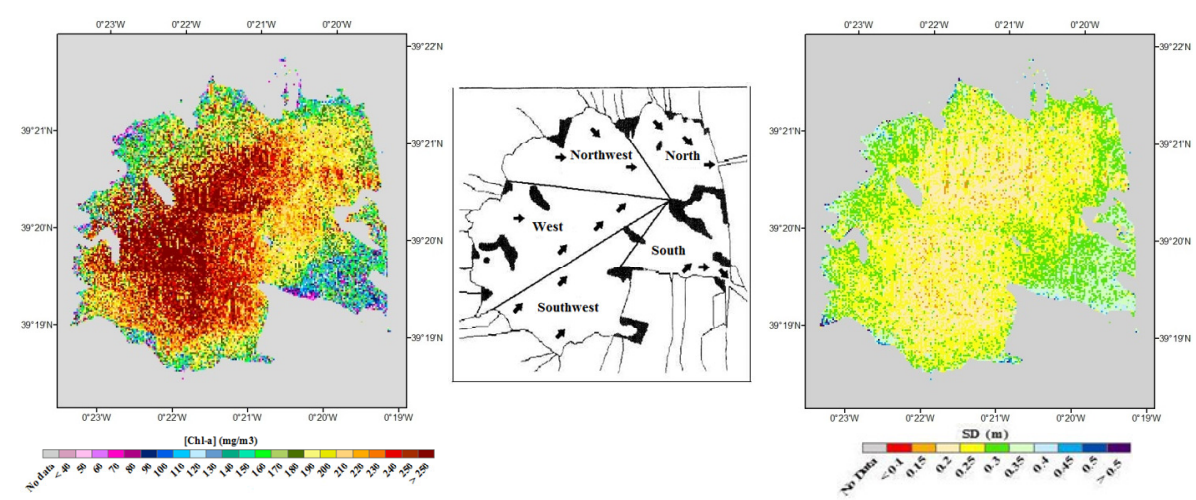

Fig. 9. Chlorophyll $a$ concentration map (left), water transparency map (right) and lake sectors proposed by Soria \& Vicente (2002) (center). 


\section{Conclusions}

Our study demonstrates that the IDFM method fusing the Landsat and MODIS images, with the aid of STAR-FM algorithm, is useful to improve the temporal resolution of Landsat images. This solves the lengthy data gap posed by Landsat, providing more intensive Earth system observations. The GP models were produced for the estimation of Chl- $a$ concentrations and water transparency simultaneously, based on the synthetic Landsat reflectance values. Satisfactory results were obtained for the estimation of Chl- $a$ and water transparency, with high correlations between the predicted values and the observed values at both training and validation stages. This IDFM drastically improves the traditional effort by means of linear regression techniques. The robustness of these GP models can be improved with the addition of more ground-truth data for training when exposing the GP models to a wider range of Chl- $a$ concentrations and water transparency data.

With the aid of IDFM, we applied such a tool to rapidly derive the heterogeneous maps addressing spatial distributions of Chl- $a$ concentration and water transparency, as well as their temporal changes in the Albufera de Valencia. In the case of our study in the Albufera de Valencia, the comparison of the spatial and temporal changes of water quality resulting in strong water management implications. It clearly offers a powerful insight that can be used to improve management practices that allow us to increase the ecological health of the lake, as required by the WFD. This advancement provides a cost-effective way for monitoring water quality in lakes, which is linked to future water resources management. Note that the cloud-cover is the primary limitation of this approach. If clouds obstruct the study area, STAR-FM cannot determine the surface reflectance. Future work may be directed toward developing a cloud removal algorithm for restoring more useful remote sensing images.

\section{Acknowledgements}

This study was jointly supported by the "Ministerio de Economia y Competitividad" by aid granted projects CGL2010-17577-CLI, CGL2013-46862-C2-1/2-P, PROMETEUII/2014/086 to VC and CGL2012-38909 to AC. The authors would like to thank Mr. Yan-Oing Dong for providing the code to solve the issue of Landsat-7 data gaps.

\section{References}


Allan, M. G., Hamilton, D. P., Hicks, B. J., Brabyn L., 2011. Landsat remote sensing of chlorophyll-a concentrations in central North Island lakes of New Zealand. Int. J. Rem. Sens. 32, 2037-2055.

Allee, R. J., Johnson, J. E., 1999. Use of satellite imagery to estimate surface chlorophyll-a and Secchi disc depth of Bull Shoals Reservoir, Arkansas, USA. Int. J. Remote Sens. 20, 1057-1072.

Alonso-Fernández, J. R., Díaz-Muñiz, C., García-Nieto, P. J., De Cos Juez, F. J., Sánchez-Lasheras, F., Roqueñí M. N, 2013. Forecasting the cyanotoxins presence in fresh waters: A new model based on genetic algorithms combined with the MARS technique. Ecol. Eng. 53, 68-78.

Bricker, S. B., Clement, C. G., Pirhalle, D. E., Orlando, S. P., Farrow, D. R. G., 1999. National Estuarine Eutrophication Assesment, Effects of nutrient enrichment in the Nation's estuaries, NOAA, September 1999, 71pp.

Caselles, V., Artiago, M. M., Hurtado, E., Coll, C., Brava, A., 1998. Mapping actual Evapotranspiration by combining Landsat TM and NOAA-AVHRR Images: Application to the Barrax Area, Albacete, Spain. Remote Sens. Environm. 63, 1-10. Chang, N. B., Vannah, B. W., Yang, Y. J., and Elovitz, M., 2014a. Integrated data fusion and mining techniques for monitoring total organic carbon concentrations in a lake. Int J Remote Sens., 35, 1064-1093.

Chang, N. B., Vannah, B. W., and Yang, Y. J. 2014b. Comparative sensor fusion between hyperspectral and multispectral satellite sensors for monitoring microcystin distribution in Lake Erie. IEEE J. Sel. Topics Appl. Earth Observ., 7, 2426-2442.

Domínguez, J. A., Alonso, C., Alonso A., 2011. Remote sensing as a tool for monitoring water quality parameters for Mediterranean Lakes of European Union water framework directive (WFD) and as a system of surveillance of cyanobacterial harmful algae blooms (SCyanoHABs). Env.Monit. Assess. 181, 317-334.

Domínguez-Gómez, J. A., Rodríguez-Pérez, D., Marcos-Martín, C., Chao-Rodríguez Y., Delgado-Rojas G., 2012. Estudio de aguas continentales mediante teledetección. UNED, Spain.

Doña, C., Sánchez, J. M., Caselles, V., Domínguez, J. A., and Camacho, A., 2014. Empirical relationships for monitoring water quality of lakes and reservoirs through multispectral images. IEEE J. Sel. Topics Appl. Earth Observ., 7, 16321641 . 
Duan, H., Zhang, Y., Zhang, B., Song, K., Wang, Z., 2006. Assessment of chlorophylla concentration and trophic state for Lake Chagan using Landsat TM and field spectral data. Environ. Monit. Assess. 129, 295-308.

Dwyer, J., Schmidt, G., 2006. The MODIS Reprojection Tool, in: Qu, J.J., Gao, W., Kafatos, M., Murphy, R. E., Salomonson, V. V. (Eds.), Earth science satellite remote sensing. Springer Berlin Heidelberg. pp. 162-177.

Environmental System Research Institute (ESRI) (2013). http://bbs.esrichinabj.cn/ESRI/viewthread.php?tid=52263\&extra=\&page=4. Accessed by Oct. 2013.

European Commission. Directive 2000/60/EC of the European Parliament and of the Council of 23 October 2000 establishing a framework for Community action in the field of water policy. Official Journal of European Communities. 327, pp. 1-72.

Francone, D.F., 1998. Discipulus Software Owner's Manual, version 3.0 DRAFT, Machine Learning Technologies, Inc., Colorado.

Gao, F., Masek, J., Schwaller, M., Hall, F., 2006. On the Blending of Landsat and MODIS Surface Reflectance: Predicting Daily Landsat Surface Reflectance. IEEE Trans. Geo. \& Remote Sens. 44, 2207-2218.

Genderen, J., Pohl, C., 1994. Image Fusion: Issues, Techniques, and Applications. Intelligent Image Fusion. Proc. EARSel Workshop, Strasbourg, France, pp. 18-26.

Gitelson, A.A., Dall'Olmo, G., Moses, W., Rundquist, D.C., Barrow, T., Fisher, T.R., Gurlin, D., Holz, J., 2008. A simple semi-analytical model for remote estimation of chlorophyll-a in turbid waters: Validation. Remote Sens. Environt. 112, 3582-3593.

Gitelson, A.A., Schalles, J.F., Haladik, C.M., 2007. Remote chlorophyll-a retrieval in turbid, productive estuaries: Chesapeake Bay case study. Remote Sens. Environ. $109,464-472$.

Härmä, P., Vepsäläinen, J., Hannonen, T., Pyhälathi, T., Kämäri, J., Kallio, K., Eloheimo, K., Koponen, S., 2001. Detection of water quality using simulated satellite data and semi-empirical algorithms in Finland. Sci. Tot. Environ. 268, 107121.

Koza, J., 1992. Genetic Programming: on the programming of computers by means of natural selection. Cambridge, MA: The MIT Press.

Lawrenz, E., Richardson, T. L., 2011. How does the species used for calibration affect chlorophyll a measurements by in situ fluorometry? Estuaries and Coasts, 34, 872883. 
López-García, M. J., Caselles, V., 1987. Use of Thematic Mapper data to assess water quality in Albufera lagoon of Valencia (Spain). Proc.13 ${ }^{\text {th }}$ Ann. Conf. of Remote Sensing Society. Nottingham, UK, pp. 510-519.

Mancino, G., Nolè, A., Urbano, V., Amato, M., Ferrara, A., 2009. Assessing water quality by remote sensing in small lakes: the case study of Monticchio lakes in southern Italy. iForest. 2, 154-161.

Margalef, R., 1983. Limnologia. Omega, Barcelona, Spain.

Masek, J.G., Vermote, E.F., Saleous, N., Rwolfe, Hall, F.G., Huemmrich, F., Gao, F., Kutler, J., Lim, T.K., 2006. A Landsat surface reflectance data set for North America, 1990-2000, Geosci. Remote Sens. Letters, 3, 68-72.

Mayo, M., Gitelson, A., Yacobi, Y. Z., Ben-Avraham, Z., 1995. Chlorophyll distribution in Lake Kinneret determined from Landsat Thematic Mapper data. Int. J. Remote Sens. 16, 175-182.

McCullough, I. M., Loftin C.S., Sader S.A., 2012. High-frequency remote monitoring of large lakes with MODIS 500 m imagery. Remote Sens. Environ. 124, 234-241.

O’Reilly, J.E., Maritorena, S., Mitchell, B.G., Siegel, D.A., Carder, K.L., Garver, S.A., Kahru, M., McClain, C., 1998. Ocean color chlorophyll algorithms for SeaWiFS. J. Geophysical Res. 103, 24937-24953.

OECD. 1982. Eutrophisation des Eaux. Methodes de surveillance, d'evaluation et de lutte (Eutrophication of water, monitoring, assessment and control). Paris, France.

Olmanson, L. G., Bauer, M.E., Brezonik, P.L., 2008. A 20-year Landsat water clarity census of Minnesota's 10,000 lakes. Rem. Sens. Environ. 112, 4086-4097.

Peña., R., Ruiz, A., Domínguez J. A., 2004. Mapping of photosynthetic pigments in Spanish inland waters using MERIS imagery. Envisat Symp. Salzburg, Austria.

Picazo, A., Rochera, C., Vicente, E., Miracle M.R., Camacho A., 2013. Determination of photosynthetic pigments by spectrophotometric methods in stratified lakes: a critical analysis based on comparisons with HPLC determinations in a model lake. Limnetica 32, 139-158.

Pinto, A. M. F., Von Sperling, E., Moreira, R. M., 2001. Chlorophyll-a determination via continuous measurement of plankton fluorescence: methodology development. Wat. Res. 35, 3977-3981.

Pohl, C., and Van Genderen, J., 1998. Multisensor image fusion in remote sensing: Concepts, methods, and applications. Int. J. Remote Sens. 19, 823-854. 
Romo, S., García-Murcia, A., Villena, M. J., Sánchez, V., Ballester A., 2008. Phytoplankton trends in the lake of Albufera de Valencia and implications for its ecology, management, and recovery. Limnetica, 27, 11-28.

Seifert, J., 2004. Data Mining: An Overview. CRS Report for Congress.

Serrano M. L.; Camacho, A., Vicente, E., Peña, R., 1997. Estudio por teledetección de la evolución del estado trófico de tres embalses del ámbito de la Confederación Hidrográfica del Júcar en el periodo estival de los años 1994 y 1995. Limnetica 13, 5-14.

Siegel, D. A., Wang, M., Maritorena, S., Robinson, W., 2000. Atmospheric correction of satellite ocean color imagery: The black pixel assumption. Applied Optics. 39, $3582-3591$.

Soria, J. M., Vicente, E., 2002. Estudios de los aportes hídricos al parque natural de la Albufera de Valencia (Studies of water flow contribution to the natural park of la Albufera de Valencia). Limnetica, 2, 105-115.

Strickland, J. D. H., Parsons, T. P., 1986. A practical handbook for seawater analysis. Fisheries Research Board. Ottawa, Canada.

Vermote, E.F., Tanre, D., Deuze, J.L., Herman, M., Morcrette, J.J., 1997. Second simulation of the satellite signal in the solar spectrum, 6S: an overview. IEEE Trans. Geosci. \& Remote Sens. 35, 675-685.

Vicente E., Miracle, M. R., 1992. The coastal Lagoon Albufera de Valencia: an ecosystem under stress. Limnetica, 8, 87-100.

Willmott, C.J., 1982. Some comments on the evaluation of model performance. Bull. Amer. Meteor. Soc. 11, 1309-1313. 


\section{Appendix 1. Chorophyll $a$ GP algorithm}

The resulting GP algorithm derived using the fused band data is given below. Due to the equation's lengthy complexity, variables $X_{1}$ to $X_{25}$ have been introduced to simplify it. The variables $v_{0}, v_{1}, v_{2}, v_{3}, v_{4}$, and $v_{5}$ correspond to the surface reflectance values of the synthetic images, where the spectral range of every image band correspond to: $v_{0}=$ Landsat B1, $v_{1}=$ Landsat B2, $v_{2}=$ Landsat B3, $v_{3}=$ Landsat B4, $v_{4}=$ Landsat B5 and $v_{5}=$ Landsat B7.

$$
\text { Chl } a=60.9-\left(153 *\left(F 2 X M 1\left(X_{25}\right)\right)\right)
$$

where $X_{1}$ to $X_{25}$ are as follows:

$$
\begin{aligned}
& X_{1}=\sin \left(2 v_{4}-2 v_{5}\right) \\
& X_{2}=v_{4}-v_{5} \\
& X_{3}=\left(X_{2}+X_{1}-1.20 f i x\left(X_{2}+3 X_{1}\right)^{2}\right)^{2} \\
& X_{4}=v_{4}-v_{2}+X_{3} \\
& X_{5}=\operatorname{abs}\left(\frac{16 X_{4}}{v_{0}}+31.8\right) \\
& X_{6}=2 v_{45}-2 f i x\left(v_{4}-18.9 X_{5}\right) \\
& X_{7}=\frac{2 X_{4}}{v_{0}}-f i x\left(X_{6}\right) \\
& X_{8}=\frac{2}{X_{3}}+1.08 \\
& X_{9}=X_{7}-f i x\left(V_{4}-18.9 X_{5}\right) \\
& X_{10}=v_{4}+\left(X_{2}+X_{1}-1.20 f i x\left(X_{2}+3 X_{21}\right)^{2}\right) \\
& X_{11}=X_{9}-\frac{\left(\frac{X_{10}}{v_{4}+X_{8}}+X_{8}\right)}{X_{4}}+3.98 \\
& X_{12}=v_{4}+v_{5}-18.9 X_{5}+X_{11} \\
& X_{13}=2 *\left(v_{1}+\sin \left(v_{4}+f i x\left(X_{6}\right)\right)\right) \\
& X_{14}=\left(v_{4}+2 v_{5}-18.9 X_{5}+\frac{X_{13}}{X_{12}}+X_{11}\right) \\
& X_{15}=\frac{\left(\frac{X_{10}}{v_{4}+X_{8}}+X_{8}\right)}{X_{4}} \\
& X_{16}=8 *\left(v_{1}+\sin \left(v_{4}+f i x\left(X_{6}\right)\right)\right)
\end{aligned}
$$




$$
\begin{aligned}
& X_{17}=X_{15}+\frac{F 2 X M 1\left(4 v_{5}+\frac{X_{16}}{X_{12}}\right)}{X_{14}}-3.98 \\
& X_{18}=18.9 X_{5}-2 v_{5}-v_{4}-\frac{X_{13}}{X_{12}} \\
& X_{19}=\operatorname{fix}\left(X_{6}\right)+f i x\left(v_{4}-18.9 X_{5}\right)+X_{17} \\
& X_{20}=4 *\left(2 v_{1}+11.4 \cos \left(X_{18}-\frac{2 X_{4}}{v_{0}}+X_{19}\right) * X_{14}\right) \\
& X_{21}=\frac{2.17 *\left(2 v_{5}+\frac{X_{20}}{X_{14}}\right)^{2} * X_{14}}{v_{0}^{2}} \\
& X_{22}=v_{2}+X_{21} \\
& X_{23}=57.1 F 2 X M 1\left(\frac{4 X_{22}}{v_{3}}-5.26\right) \\
& X_{24}=\operatorname{abs}\left(v_{2}-v_{4}=X_{23}-\frac{18.9 X_{14}}{v_{2}+\frac{X_{21}}{v_{0}}-5.51}\right) \\
& X_{25}=v_{5}-75.6 * a b s\left(\frac{4 X_{24}}{v_{03}}\right)
\end{aligned}
$$

Note: $a b s()$ is the absolute value of the parenthetic expression. The $f i x()$ expression rounds the value down to the nearest integer value. $F 2 X M 1()$ is an exponential function; if the absolute value of the parenthetic expression is less than or equal to 1 , then the F2XM1 instruction calculates two raised to the $\mathrm{f}(\mathrm{x})$ power, minus one. This expression is as follows:

$$
F 2 X M 1=\left(2^{x}-1\right) ; \operatorname{abs}(x) \leq 1
$$

\section{Appendix B. Water Transparency GP algorithm}

The resulting GP algorithm derived using the fused band data is given below. Due to the equation's lengthy complexity, variables $X_{1}$ to $X_{10}$ have been introduced to simplify it. The variables $v_{0}, v_{1}, v_{2}, v_{3}, v_{4}$, and $v_{5}$ correspond to the surface reflectance values of the synthetic images, where the spectral range of every image band correspond to: $v_{0}=$ Landsat B1, $v_{1}=$ Landsat B2, $v_{2}=$ Landsat B3, $v_{3}=$ Landsat B4, $v_{4}=$ Landsat B5 and $v_{5}=$ Landsat B7. 


$$
S D=X_{10}-6 X_{6}-\frac{2 X_{3}}{X_{1}}
$$

where $X_{1}$ to $X_{10}$ are as follows:

$$
\begin{aligned}
& X_{1}=\cos \left(X_{3}^{2}\right) \\
& X_{2}=1.2 * v_{2}-v_{0} \\
& X_{3}=\sin \left(9.45 v_{3}-v_{5}-7.36\right) \\
& X_{4}=v_{5} *\left(2 X_{6}^{2}+3.29\right) \\
& X_{5}=\operatorname{abs}\left(\frac{3 X_{3}}{X_{1}}+X_{4}\right) \\
& X_{6}=\cos \left(\frac{F 2 X M 1\left(X_{2}\right)}{v_{4}}\right) \\
& X_{7}=\left(\frac{1.05 *\left(\frac{2 X_{2}}{X_{1}} 3.98\right)}{X_{6}}\right) \\
& X_{8}=\frac{\left(4 X_{6}-X_{7}\right)^{2}}{X_{5}} \\
& X_{9}=\frac{1.09 X_{5}}{4.0 * X_{6}-X_{8}}-4.35 X_{6}+X_{8} \\
& X_{10}=\left(v_{1}+1.09 * a b s\left(X_{9}\right)\right)^{1 / 2}
\end{aligned}
$$

Note: $a b s()$ is the absolute value of the parenthetic expression. The fix() expression rounds the value down to the nearest integer value. F2XM1() contains a conditional nested within a higher-tiered conditional. $F 2 X M 1()$ is an exponential function; if the absolute value of the parenthetic expression is less than or equal to 1 , then the F2XM1 instruction calculates two raised to the $\mathrm{f}(\mathrm{x})$ power, minus one.

This expression is as follows:

$$
F 2 X M 1=\left(2^{x}-1\right) ; \operatorname{abs}(x) \leq 1
$$

